\title{
The Role of Educational Leaders in Supporting the Mental Health of All Students
}

\author{
Jessica Whitley \\ University of Ottawa
}

\begin{abstract}
There has been recent attention paid to the mental health issues experienced by many children and youth in Canada and internationally. In particular, the role of the school and educational leaders in preventing mental health difficulties and intervening in the case of mental illnesses has been highlighted. This paper presents an overview of several policies, programs, and initiatives related to the prevention of and intervention for mental health difficulties in Canadian schools with a focus on the Ontario context. Following this, literature examining the role of educational leaders in meeting the mental health needs of students will be reviewed and recommendations put forward.
\end{abstract}

In Canada, prevalence rates of children and youth experiencing mental health difficulties, including mental illnesses, such as anxiety, depression, or attention-deficit/hyperactivity disorder, are estimated to be at approximately $15 \%$ to $20 \%$ (Arboleda-Flórez, 2005; Waddell \& Shepherd, 2002). As well, suicide is the second leading cause of death among youth in Canada, with rates five to seven times higher for First Nations youth and 11 times higher for Inuit youth (Health Canada, 2006). Of the millions of children and youth in Canada who suffer from mental health issues, it has been reported that only one in five receive treatment (UNICEF Canada, 2007).

There are a number of reasons why the mental health needs of children and youth are not currently being met. Many of these are documented in recent Canadian reports including Out of the Shadows at Last: Transforming Mental Health, Mental Illness and Addiction Services in Canada (Kirby \& Keon, 2006), A Shared Responsibility: Ontario's Policy Framework for Child and Youth Mental Health (Ontario Ministry of Child and Youth Services, 2006), and Taking Mental Health to School: A Policy-Oriented Paper on School-based Mental Health for Ontario (Santor, Short, \& Ferguson, 2009). These reports echo the perspective of the recent wider professional and research literature (e.g., U.S. Department of Health and Human Services, 2001), which looks beyond a traditional and narrow focus on mental health as simply the absence of mental illness to a definition of 
a state of well-being in which the individual realizes his or her own abilities, can cope with the normal stresses of life, can work productively and fruitfully, and is able to make a contribution to his or her own community. (World Health Organization, 2009, para. 1)

Currently, many Canadian children do not experience positive mental health outcomes and instead display indicators of impaired well-being including psychological distress, engagement in physical violence, and suicidal ideation (Adlaf, Paglia-Boak, Beitchman, \& Wolfe, 2007; Santor et al., 2009).

The majority of the literature documenting the lack of appropriate mental health services for children and youth has come from various segments of the health care sector, rather than the education system. This is to be expected, given the historical role of health care and communitybased organizations in providing for individuals dealing with mental health issues and mental illnesses (Waddell, Offord, Shepherd, Hua, \& McEwan, 2002). Although some schools offer onsite counselling and the services of professionals, such as social workers and psychologists, the mandate of schools has traditionally focused on academic, rather than psychological, outcomes for students. Recently, however, a growing awareness of the mental health difficulties faced by children and youth (Coulman, 2003; Santor et al., 2009; Waddell \& Shepherd, 2002; World Health Organization, 2001) and the recognition of the key role that schools can play in providing services to these students (Kirby \& Keon, 2006; Ontario Ministry of Child and Youth Services, 2006) have prompted a series of related reports, policy documents, and school-based initiatives (e.g., Adelman \& Taylor, 2008; Canadian Council on Learning, 2009; Hoagwood et al., 2007).

These sources typically adopt an interdisciplinary perspective in addressing mental health needs of children and youth with the understanding that traditional, 'silo'-based policy and practice is ineffective and insufficient (Kirby, 2005). These also highlight the key role of educational leaders, including school principals, in planning, implementing, and sustaining the changes necessary to ensure that schools are working collaboratively with their community-based partners in a concerted effort to improve the well-being for students.

Although multiple documents exist, there has not been a review of the status of school involvement, and particularly that of school leaders, in mental health service provision in Canada. The present paper will first present an overview of several policies, programs, and initiatives related to the prevention of and intervention for mental health difficulties in Canadian schools, with a focus on the Ontario context in particular. Following this, literature examining the role of educational leaders in meeting the mental health needs of students will be reviewed and recommendations put forward. Given the paucity of education literature related to mental health in Canada, it is hoped that this paper will generate discussion and inform next steps in terms of research, training, and practice.

\section{Canadian Context}

The provision and funding of health care services, including mental health, is the mandate of provincial/territorial, rather than federal, ministries and departments. Each province/territory has developed individual methods of addressing mental health concerns of children and youth in particular. For example, British Columbia's Mental Health and Addictions Services, Alberta Health Services, and Nova Scotia's Department of Health coordinate both inpatient and community-based psychiatric services for children and youth (Alberta Health Services, 2010; BC Mental Health \& Addiction Services, 2010; Nova Scotia Department of Health, 2010). Within these services, some provinces/territories have included specific provision for col- 
laboration or engagement with education staff as part of an interdisciplinary approach (e.g., Alberta Health Services, 2010; Saskatchewan Health, 2007).

Even within the provinces and territories, however, there is considerable variation in the types of services available and the ways in which services are delivered to children and youth. As noted by the Canadian Paediatric Society (2009), most provinces/territories do not have mental health plans that specifically focus on the unique needs of children and youth. According to this organization, "About $70 \%$ of mental illnesses have their onset in childhood or adolescence, reinforcing the importance of early monitoring, prevention and treatment to reduce their potential lifelong impact" (Canadian Paediatric Society, 2009, p. 5). The Canadian Paediatric Society also conducted a ranking of provinces/territories in terms of the quality of their mental health plan for children and youth; criteria include wait time specifications, mental health promotion components, and the involvement of community paediatricians. No provinces/territories received the highest ranking of "Excellent," while five of these including British Columbia, Saskatchewan, and Quebec received the next best "Good" ranking.

While reflecting the perspective of a single interest group, the Canadian Paediatric Society report does highlight the real variation in the type and quality of services and policies that exist across Canada with respect to the mental health needs of children and youth. In recognition of this, there have been reports issued recently that take a national focus on mental health issues across the lifespan. In particular, Out of the Shadows at Last summarizes the findings and recommendations of the Standing Senate Committee on Social Affairs, Science and Technology, chaired by Kirby and Keon (2006) from their investigation into the status of mental health in Canada. Their report is wide-ranging both in terms of the issues explored and the age-range of the individuals focused on. The section relating specifically to children and youth highlights the fragmented and under-funded nature of the mental health system.

The issue of fragmentation is of particular importance for school-aged children for whom early intervention and prevention of escalating mental health difficulties is paramount (McEwan, Waddell, \& Barker, 2007; Waddell, Peters, Hua, McEwan, \& Garland, 2007). According to McEwan and her colleagues (2007), "Mounting research evidence suggests that childhood is the optimal time to influence determinants of social and emotional well-being" (p. 471). It can be overwhelming for parents to seek out the various sources of community-based service delivery and to coordinate these in a timely manner for their child while still maintaining close ties with educators and possibly also special education personnel. As mental health services for children are currently offered by a variety of "different 'silos' that inhibit integration into a true continuum of care" (Kirby, 2005, p. S6), it is not surprising that many children and youth fail to receive adequate treatment.

Given these systemic barriers to treatment, the role of the school in mental health service provision has become the focus of increasing discussion. Out of the Shadows at Last (Kirby \& Keon, 2006) includes the following statement from Dr. Richard Goldbloom, Professor of Paediatrics at Dalhousie University:

I see the school as the most underdeveloped site for effective health care of any in the country...we need a major move of mental health services from their present locations in most communities into the schools. The school is children's natural habitat. For six or eight hours a day, it is where they are, it is where their parents often come and it is where you can deal with the problems in collaboration with the teachers. (Kirby \& Keon, 2006) 
Testimony from other experts in the field echoed those of Dr. Goldbloom. As a result of the evidence presented, a number of recommendations were developed specifically relating to the provision of mental health services in the schools:

- That school boards mandate the establishment of school-based teams made up of social workers, child/youth workers, and teachers to help family caregivers navigate and access the mental health services their children and youth require, and that these teams make use of a variety of treatment techniques and work across disciplines.

- That mental health services for children and youth be provided in the school setting by the school-based mental health teams recommended...above

- That teachers be trained so that they can be involved in the early identification of mental illness.

- That teachers be given the time and the practical resources and supports necessary to take on this new role.

- That students be educated in school about mental illness and its prevention, and that the Canadian Mental Health Commission work closely with educators to develop appropriate promotion campaigns in order to reduce stigma and discrimination.

As a result of these recommendations, a number of initiatives were developed, particularly with reference to the final recommendation that suggests implementing education and awareness programs to students. The Canadian Mental Health Association (2007), as one example, created a curriculum guide for secondary school students focused on understanding mental health and mental illness. The responsibility for education and health, however, lies within the mandate of individual provinces and territories where a range of programs and policies related to mental health in schools continue to emerge.

\section{Ontario Context}

In Ontario, in addition to Ministries of Education, Community and Social Services and Health and Long-Term Care, a Ministry of Children and Youth Services (MCYS) was created in 2003. This Ministry provides funding for child welfare, family intervention services, youth justice services, children's community support services, children's mental health services, and child care. With specific reference to its mental health mandate, the MCYS has described a framework for service provision in a 2006 document: A Shared Responsibility: Ontario's Policy Framework for Child and Youth Mental Health.

One of the basic tenants of the framework is that the "mental health of Ontario's children and youth does not depend on the child and youth mental health sector alone. Instead, it is a shared responsibility" (Ontario Ministry of Children and Youth Services, 2006, p. 1). The education sector is one essential collaborator listed by MCYS and its potential roles include providing public education programs (i.e., anti-stigma) to students, partnering with MCYS and other organizations to better integrate programs, facilitating transitions, and developing positive connections with children and youth.

There are many ways, including those listed in the Shared Responsibility document, for schools to partner or collaborate with other professionals and organizations to develop interventions for students struggling with mental health difficulties and illness. In Ontario schools, however, as in most schools across the country, the greatest roles played in relation to mental health services are (a) the prevention of mental health problems and the promotion of mental health through the development of protective factors and (b) referring students at-risk to appropriate service providers. With respect to the former, mental health promotion refers to giving students the tools they need to navigate relationships, cope with stress, manage emotions, problem-solve, and make safe choices. Although not typically labelled as mental health programs, 
initiatives and curriculum that develop these types of skills certainly contribute to positive psychosocial outcomes for children and youth and mental health broadly (e.g., Merry, McDowell, Wild, Bir, \& Cunliffe, 2004; Shochet et al., 2001).

Mental health promotion also includes development on the part of students and staff of an understanding of mental health issues and the harmful effects of stigma in particular. Discriminatory attitudes, which are often displayed towards individuals with mental health difficulties (Angermeyer \& Dietrich, 2006; Wahl, 2002), can serve to exacerbate symptoms and inhibit helpseeking behaviour (Corrigan \& Kleinlein, 2005).

A few examples of initiatives in Ontario that include elements of mental health prevention or promotion include several developed by the Ontario Ministry of Education including Healthy Schools (2010), Safe Schools (2008b), Character Development (2008a), and the Student Success Strategy and the Student Support Leadership initiative (Steenkamp \& Wright, 2008). As another example, the Ontario Physical and Health Education Association (2010) created the Living Schools initiate, which facilitates school-based comprehensive health programming with the aim of addressing risk factors for chronic disease and obesity.

The Ontario Ministry of Education's Healthy Schools initiative, while largely focused on physical health including healthy eating and increased physical activity, also includes a segment targeting mental health. Schools are encouraged to find ways to support the mental health of students by (a) raising awareness and educating staff and students about mental health issues; (b) creating an environment for students that promotes mental health; and (c) collaborating with the community to share information about available services.

A number of schools in Ontario have applied to the Healthy Schools Recognition program to have their mental health initiatives highlighted by the Ministry. Examples range from skill building curricula, such as the "7 Habits for Highly Effective Teens" program, to a variety of educational presentations and programs related to mental illnesses (Ontario Ministry of Education, 2010).

This initiative by the Ministry of Education is aligned with other initiatives in Ontario that have as their goal the promotion of health from a broad perspective, which includes "the physical, mental, social and spiritual health of the whole school community and constantly strengthens its capacity as a healthy setting for living, learning and working" (Ontario Public Health Association, 2008). The Ontario Healthy Schools Coalition (2008), supported by the Ontario Public Health Association, promotes and supports the development of Healthy Schools in Ontario and contributed to the Foundations for a Healthy School framework adopted by the Ontario Ministry of Education.

With respect to coordinating or facilitating referrals for mental health issues, Ontario has also funded the Student Support Leadership initiative (Steenkamp \& Wright, 2008). This is an approach taken by the Ontario Ministry of Education in partnership with the Ontario Ministry of Children and Youth Services to meet the non-academic needs of students. The initiative is designed to support and promote positive student behaviour and is aligned with the Safe Schools Strategy and the Shared Responsibility policy framework. Through the Student Support Leadership initiative, geographic clusters consisting of school boards and community agencies are offered up to 3 years of funding to develop the leadership necessary to develop collaborative models to meet the needs of students.

Leadership is the focus of the initiative as it "is a critical requirement for developing collaborative partnerships between school boards, schools and community service providers" (Pervin \& Gitterman, 2008). Through leadership, local partners will be able to: 
- share expertise;

- improve decision-making through effective planning mechanisms;

- establish or enhance referral mechanisms and effective case management practices;

- increase access to appropriate services and supports for students and families;

- improve a student's and family's ability to understand, navigate and use the services and supports available to them; and

- improve service outcomes for students using mental health supports. (Pervin \& Gitterman, 2008, p. 1)

Healthy Schools and the Student Support Leadership initiative are just two initiatives that are focused on promoting mental health among Ontario students. Many others are ongoing, at local and provincial levels. Several Ontario board-level initiatives are described in a provincial scan conducted by Santor and her colleagues (2009) with respect to building awareness and mental health literacy, promoting prevention and intervention programs, and facilitating innovative systems of mental health service delivery. While many boards described being in the very early stages of planning in many of these areas, some key strategies were highlighted in various regions. For example, a collaborative approach to developing and delivering mental health information resources in schools is ongoing in Hamilton as part of the Student Support Leadership initiative. In Ottawa, a coalition of school boards, municipal and provincial governments, and the United Way was formed to implement comprehensive drug and alcohol prevention and treatment programs in area high schools; currently substance use counsellors spend 14 hours per week in every school. In the Thames Valley District School Board, an interdisciplinary mental health committee was established to coordinate student mental health services and to work with the Student Support Leadership initiative partners.

The approaches of the Student Support Leadership and Healthy Schools, as well as the initiatives being developed by individual boards across Ontario reflect recognition of the need for school-wide mental health promotion and comprehensive integrated student supports as well as the crucial role of leaders to champion the process. What is not clear, however, is the impact of these types of locally-developed programs on student outcomes and whether they are actually fostering significant and sustained change within school cultures. It is also not evident how these various initiatives and programs fit into standard practice in schools and ways that educators and leaders have typically sought to meet the needs of students with mental health difficulties, namely special education.

\section{The Role of Special Education}

The special education system is the venue that has traditionally served students with mental health difficulties and mental illness within schools (Coulman, 2003; Rothi, Leavey, \& Best, 2008). In the United States, students who display mental health difficulties that are chronic and pervasive and that negatively impact on their educational performance are identified within the special education category "Emotional Disturbance" (National Dissemination Center for Children with Disabilities, 2008). The United Kingdom refers to behavioural, emotional, or social difficulties (Rothi et al., 2008). In Canada, students displaying these types of difficulties may be identified within several categories of exceptionality including, for example, Behaviour (Ontario), Emotional/Behavioural Disability (Alberta), Behavioural Needs or Mental Illness (British Columbia), Emotional/Behavioural Disorders (Nova Scotia, Manitoba, Newfoundland and Labrador). 
The services that students receive as a result of being identified within an emotional and/or behavioural category vary widely both within and across provinces and territories and depend on local priorities, available funding, and the level of severity of the difficulty. However, as with all special education categories most include the provision of an Individual Education or Program Plan. This plan may include particular accommodations and strategies that assist the student in developing, for example, prosocial behaviours, social skills, problem-solving, and coping skills (British Columbia Ministry of Education, 2009; Ontario Ministry of Education, 2002). Other services may include placement in specific behaviour classes, transition programs, and alternate education programs (Coulman, 2003; Ottawa Carleton District School Board, 2009).

In some instances, the needs of students may be met through this referral, identification, and placement/program process. However, the needs of students with mental health issues are often complex and require more than changes to educational programming and the support of teachers (Arboleda-Flórez, 2005; Waddell \& Shepherd, 2002). As well, many mental health difficulties develop in adolescence and may be dealt with using disciplinary policies, rather than being viewed as symptoms of underlying emotional issues (Santor et al., 2009). The poor educational and psychological outcomes that continue to be reported for these students (Wagner, Kutash, Duchnowski, Epstein, \& Sumi, 2005) and the growing numbers of students experiencing mental health issues indicate that more can be done. Furthermore, there is evidence that schools that provide mental health services to students may see a reduction in special education referrals for emotional and behavioural difficulties (Bruns, Walrath, Glass-Siegel, \& Weist, 2004) indicating positive changes in classrooms. What is not clear, however, is how the policies and practices within the realm of special education align within those targeting mental health and mental illness - particularly when these may concern the same students. Some Ministries of Education, such as in Manitoba and British Columbia, have processes in place to support students with severe emotional/behavioural disorders as part of a coordinated multisystem plan including family members and representatives from various service sectors (British Columbia Ministry of Education, 2009; Manitoba Education, Citizenship and Youth, 2009). Although part of standard special education practice, the recognition that students with serious mental health issues require educators to work as part of a team allows for greater integration of health care providers and plans in a planned, systemic fashion.

The many initiatives that exist both in and outside of Ontario reflect a real commitment of the education sector, in partnership with other ministries and community organizations, to making a difference in the lives of vulnerable and at-risk children and youth, including those with mental health issues and mental illness (e.g., British Columbia Ministry of Education, 2009; Steenkamp \& Wright, 2008). However, given the competing demands that exist within schools, the lack of apparent alignment in some provinces of mandated special education services and mental health initiatives, the long-term support and efficacy of these is not assured. In particular, those programs and approaches that do not target students who are struggling overtly in terms of academics and behavioural concerns, but focus rather on internalizing behaviours (anxiety, depression) and prevention, are likely at the greatest risk of becoming transient. In addition to a continued focus and prioritizing by provincial and federal bodies, there are a number of board and school-level elements that are necessary.

Many schools may be involved in pilot projects arising from new initiatives such as those listed previously. However, "the history of schools is strewn with valuable innovations that were not sustained" (Center for Mental Health in Schools, 2007, p. 1). In order for mental health ser- 
vices to become an integral part of what is offered by schools, not an extra or temporary role, there needs to be an ongoing commitment made by educational leaders.

Educational leaders, including school principals and vice-principals, presently deal with mental health issues on a daily basis in the form of special education referrals, behaviour problems, school violence, bullying, absences, drop-outs, and low achievement (Adelman \& Taylor, 2000; Epstein et al., 1993). As has been mentioned, there are a number of interventions in place, many supported by Ministries of Education, to address these issues. What is essential, however, is that a long-term strategy adopted by schools and boards focuses on the mental health needs of all of its students, not simply those who are overtly struggling (Waxman, Weist, \& Benson, 1999). Research conducted largely in the United States and Australia as well as observations of educators and mental health practitioners throughout North America have identified a number of ways in which educational leaders can support whole school, sustainable approaches to promoting mental health for students.

\section{The Role of Educational Leaders}

According to O'Brien, Weissberg, and Shriver (2003), "educational leaders need to respond to these diverse challenges in a coherent and effective way that recognizes the reality of children and schools, as well as of the society in which we now live" (p. 24). There are many ways that educational leaders can develop a comprehensive approach to supporting the mental health needs of students. Four of these are outlined below.

\section{Establish an Infrastructure}

Clearly, finding ways to support the mental health needs of students requires long-term, consistent, and concerted efforts on the part of many individuals, including educational leaders. However, one of the difficulties with new school-based initiatives, particularly those supported by short-term funding, is the tendency for them to be viewed as temporary or 'just another reform' (Adelman \& Taylor, 2006; O'Brien et al., 2003). The need for capacity building is clear, but what is also necessary is change at the organizational level in order to develop cultures based on a common understanding of mental health (Fullan, 2008).

Ensuring a shared vision by school stakeholders is key to ensuring the success of any initiative, particularly those not directly linked to academic outcomes. Involving school personnel in the development of a mission statement that includes a focus on mental health will help ensure shared commitment and motivation. As well, there is widespread agreement that one of the key elements of building successful initiatives to support mental health is the creation of steering groups and/or leadership teams that "have accepted responsibility and accountability for ensuring that the vision...is not lost and barriers to progress are removed" (Center for Mental Health in Schools, 2007, p. 2). Teams should include both school and community-based members and work to create blueprints with both short and long-term goals. School leaders can help ensure the success of the groups by taking part and also by allowing time for school staff to participate.

In order for schools to fully support students' mental health needs, there may need to be "shifts in prevailing policy and new frameworks for practice" (Adelman \& Taylor, 2000; Center for Mental Health in Schools, 2005, p. 120). O'Brien and her colleagues (2003) described the common pitfalls of a reactive or 'war on the problem' approach to issues such as mental health 
difficulties. One of these is the creation of various programs or initiatives that target different aspects of the same children. For example, a student with an identified emotional/behavioural difficulty may receive mental health services from a school or community counsellor or social worker, participate in social skills and behavioural programming with school staff as part of his or her IEP, take part in a restorative justice program, and be included in an anti-bullying initiative. Without a coordinated effort and a school-wide recognition of the common underlying causes of the mental health difficulties, positive change is unlikely to be sustained for these students (Greenberg, Domitrovich, \& Bumbarger, 2001). This perspective is echoed by Adelman and Taylor (2000): "Effectively addressing barriers to development, learning, and teaching requires a comprehensive, multifaceted continuum of community and school programs and encompasses a holistic and developmental emphasis and ranges from primary prevention and early-age intervention..." (p. 175).

Recognizing that a comprehensive mental health approach involves continuity across policies and practices in terms of, as examples, dealing with learning and behaviour problems, valuing and emphasizing student strengths in instruction and assessment, emphasizing social and emotional learning, working closely with families, and communicating regularly with medical professionals is an important first step for educational leaders. All of these elements contribute to the development of a positive climate that supports the development of student well-being. As Han and Weiss (2005) stated, "Knowledgeable and supportive school leadership can be instrumental in making a program a priority within the school, as reflected in the time, resources, incentives, and training allocated for the program as well as the expectation of accountability" (p. 668). Accordingly, resources, in the form of finances, personnel, and space may need to be redeployed to ensure the success and sustainability of the initiative(s).

\section{Build Capacity}

School leaders can also contribute to the success of comprehensive approaches to mental health promotion and intervention for students by providing both in-service and communitybased training for school staff (Ontario Ministry of Children and Youth Services, 2006; Skalski $\&$ Smith, 2006). Community partners can work with educators to find ways to develop environments that support the mental health of students through positive behavioural supports and a focus on social and emotional learning (Elias, O'Brien, \& Weissberg, 2006; O'Brien et al., 2003; Sherman, 2008; Stern, 2009). Numerous studies have shown the significant impact that schoolbased mental health prevention programs involving teachers can have on reducing problem behaviours and poor psychosocial adjustment and increasing positive outcomes such as social competence and academic achievement (Domitrovich \& Greenberg, 2000; Hawkins, Von Cleve, \& Catalano, 1991; Merry et al., 2004; Twemlow et al., 2001; Wyn, Cahill, Holdsworth, Rowling, \& Carson, 2000).

In-service training can also be delivered to school staff to provide the information they need regarding how to recognize signs and symptoms of mental health difficulties and what immediate interventions to use when students are displaying these (Meldrum, Venn, \& Kutcher, 2009; Ontario Healthy Schools Coalition, 2008; Ontario Ministry of Children and Youth Services, 2006). Teachers and administrators have reported a lack of knowledge and confidence in their teaching when it comes to mental health issues and have also expressed a need for further training and professional development in this area (Rothi et al., 2008; Santor et al., 2009; Walter, Gouze, \& Lim, 2006). As with prevention programs, teachers have also been found to be effec- 
tive as members of collaborative teams targeting the mental health needs of students at-risk or those with diagnosed mental illnesses (Hoagwood \& Erwin, 1997; Rones \& Hoagwood, 2000; Stein et al., 2002). Skalski and Smith (2006) suggested that principals assess the capacity of their staff to respond to mental health needs by asking questions such as:

Are staff members familiar with the early warning signs of emotional and behavioral health programs? Do staff members know how to respond when students share sensitive personal information? Do staff members know who the mental health professionals are in their building and how they can help students? Do the policies and procedures of the school help teachers and students respond to mental health needs, including those that reach crisis proportions? (p. 13).

Also, some staff with particular expertise or interest may become trained in the delivery of programs to students to develop skills that prevent mental health difficulties (i.e., coping, emotional awareness, problem-solving) and to enable them to recognize mental health difficulties. Providing time and resources for staff to engage in this type of training is a key role for leaders.

What is also key in terms of capacity building among staff is the dedication by leaders to work towards sustainable change through the development of professional learning communities. It is unrealistic to assume that teachers and administrators attending workshops will automatically result in the practice and policies of individual teachers and the school at large reflecting a focus on mental health promotion and prevention. In order for real changes in school cultures to take place, individuals within the school, and leaders in particular, need to engage in continuous learning by observing each others' practice, discussing and reflecting upon various approaches and strategies, and sharing with other schools engaging in similar processes (Dufour, Dufour, Eaker, \& Many, 2006; Fullan, 2002). According to Fullan (2002) "information, of which we have a glut, only becomes knowledge thorough a social process" (p. 18). Professional learning communities have typically focused on improving student learning and reducing the gaps between those experiencing academic success from those who are not (Dufour, 2004; Joyce, Calhoun, \& Hopkins, 1999). As teachers work collaboratively within a model of continuous learning demonstrated and facilitated by the principal, information about ways to support the mental health needs of students is more likely to become engrained in the fabric of the school culture rather than at surface-level.

\section{Partner with the Community}

It is a reality that many schools do not have the expertise or mandate to address the mental health difficulties of students. However, many individuals and groups in the wider community specialize in exactly this. Inviting the community into the school and working in collaboration with key partners can facilitate the delivery of both prevention and intervention services to students (Meldrum et al., 2009).

Providing and facilitating access to a continuum of services that includes both schoolwide mental health promotion as well as interventions for students with more severe needs is a key role of school leaders (Levesque \& Manion, 2006; Ontario Ministry of Children and Youth Services, 2006; Skalski \& Smith, 2006). As well, inviting community partners into the school to be visible on a regular basis and to deliver programs for staff, as previously mentioned, and also to students, can be helpful. Anti-stigma and mental health and mental illness education programs, such as those developed by the Canadian Mental Health Association (2007) and the Centre for 
Addictions and Mental Health (1998), are designed for students at specific grade levels and are provided free for schools. Allowing time for these programs to take place as well as finding ways to integrate learning into the curriculum as not to take away from valuable classroom time, can lessen the burden on teachers as well (Meldrum et al., 2009; Ontario Ministry of Children and Youth Services, 2006).

One of the simplest ways that educational leaders can provide support to students in schools is by making sure that information is available to them. Many organizations provide pamphlets describing common types of mental illness (e.g., Canadian Mental Health Association, 2009) as well as information about services that are available to children and youth with or without a referral. Just knowing that help is available and where it can be accessed is a key element in the likelihood that children and youth will receive the interventions they require (Levesque \& Manion, 2006).

\section{Develop Evidence}

Finally, one of the recommendations of the Ontario Ministry of Education (2007) is that schools provide access to researchers to examine mental health issues and support available in the school. By documenting the needs of students, screening for those who require additional services, assessing the perspectives of school personnel, and evaluating the efficacy of pilot programs, researchers from local universities and/or community organizations can work in partnership with schools to provide evidence to support future planning (Skalski \& Smith, 2006; Weare \& Markham, 2005).

\section{Conclusion}

There are many other ways that school leaders can support a comprehensive approach to mental health prevention and intervention in schools. Recognizing the integral role of the school in a collaborative approach to meeting the needs of students and families is the first step. Establishing an infrastructure, building capacity, partnering with the community, and frequently assessing needs are complex yet potentially effective ways to continue the process. It is also essential that leaders ensure that special education services and mental health promotion and intervention programs are well aligned to serve the needs of students seamlessly. Success in terms of improving mental health outcomes for our students benefits all educational stakeholders both in the short and long-term and should be a key focus for educational leaders.

\section{References}

Adelman, H. S., \& Taylor, L. (2000). Promoting mental health in schools in the midst of school reform. Journal of School Health, 70(5), 171-178.

Adelman, H. S., \& Taylor, L. (2006). The school leader's guide to student learning supports: New directions for addressing barriers to learning. Thousand Oaks, CA: Corwin Press.

Adelman, H. S., \& Taylor, L. (2008). School-wide approaches to addressing barriers to learning and teaching. In B. Doll \& J. Cummings (Eds.), Transforming school mental health services: Population-based approaches to promoting competency and well-being of children (pp. 277-306). Thousand Oaks, CA: Corwin Press. 
Adlaf, E. M., Paglia-Boak, A., Beitchman, J. H., \& Wolfe, D. (2007). The mental health and well-being of Ontario students, 1991-2007. CAMH Research Document Series, No. 23. Toronto, ON: Centre for Addiction and Mental Health.

Alberta Health Services. (2010). Mental health and wellness services. Retrieved October 26, 2010, from http://www.albertahealthservices.ca/services.asp?pid=stype\&type $=25$.

Angermeyer, M. C., \& Dietrich S. (2006). Public beliefs and attitudes towards people with mental illness: A review of population studies. Acta Psychiatrica Scandinavica, 113(3), 163-179.

Arboleda-Flórez, J. (2005). The epidemiology of mental illness in Canada. Canadian Public Policy, XXXI Supplement, S13-S16.

BC Mental Health \& Addiction Services. (2010). Child, adolescent \& women's mental health. Vancouver, BC: Author. Retrieved October 26, 2010, from

http://www.bcmhas.ca/ProgramsServices/ChildYouthMentalHealth/default.htm

British Columbia Ministry of Education. (2009). Special education services: A manual of policies, procedures, and guidelines. Victoria, BC: Author.

Bruns, E. J., Walrath, C., Glass-Siegel, M., \& Weist, M. D. (2004). School-based mental health services in Baltimore: Association with school climate and special education referrals. Behavior Modification, 28(4), 491-512.

Canadian Council on Learning. (2009). A barrier to learning: Mental health disorders among Canadian youth. Ottawa, ON: Author. Retrieved June 26, 2010, from http://www.ccl-cca.ca/

Canadian Mental Health Association. (2007). Mental health and high school curriculum guide. Retrieved February 5, 2009, from http://www.cmha.ca/highschoolcurriculum.

Canadian Mental Health Association. (2009). Resources. Retrieved February 5, 2009, from http://www.cmha.ca/BINS/content page.asp?cid=4-42.

Canadian Paediatric Society. (2009). Are we doing enough? A status report on Canadian public policy and child and youth health. Ottawa, ON: Author.

Center for Mental Health in Schools. (2005). School improvement planning: What's missing? Los Angeles, CA: University of California at Los Angeles.

Center for Mental Health in Schools. (2007). Turning a project or pilot into a catalyst for systemic change and sustainability. Los Angeles, CA: University of California at Los Angeles.

Centre for Addictions and Mental Health. (1998). Resources for teachers and schools. Retrieved October 26, 2010, from http://www.camh.net/education/Resources_teachers_schools/index.html

Corrigan, P. W, \& Kleinlein P. (2005). The impact of mental illness stigma. In P. W. Corrigan (Ed.), On the stigma of mental illness. Practical strategies for research and social change (pp. 11-44). Washington, DC: American Psychological Association.

Coulman, J. A. (2003). Education in Ontario: Education resources and the mental health of children and youth. Toronto, ON: Canadian Mental Health Association.

Dimitrovich, C. E., \& Greenberg, M. T. (2000). The study of implementation: Current findings from effective programs that prevent mental disorders in school-aged children. Educational \& Psychological Consultation, 11(2), 193-221.

Dufour, R. (2004). What is a "professional learning community"? Educational Leadership, 61(8), 1-6.

Dufour, R., Dufour, R., Eaker, R., \& Many, T. (2006). Learning by doing: A handbook for professional learning communities at work. Bloomington, IN: Solution Tree.

Elias, M. J., O’Brien, M. U., \& Weissberg, R. P. (2006). Transformative leadership for social-emotional learning. Principal Leadership, 7(4), 10-13.

Epstein, M. H., Nelson, C. M., Polsgrove, L., Coutinho, M., Cumblad, C., \& Quinn, K. (1993). A comprehensive community-based approach to serving students with emotional and behavioral disorders. Journal of Emotional and Behavioral Disorders, 1(2), 127-133.

Fullan, M. (2002). The change leader. Educational Leadership, 59(8), 16-20.

Fullan, M. (2008). School leadership's unfinished agenda. Education Week, 27(31), 36-41.

Greenberg, M. T., Domitrovich, C., \& Bumbarger, B. (2001). The prevention of mental disorders in school-aged children: Current state of the field. Prevention \& Treatment, 4(1), ArtID 1a. 
Han, S. S., \& Weiss, B (2005). Sustainability of teacher implementation of school-based mental health programs. Journal of Abnormal Child Psychology, 33(6), 665-679.

Hawkins, J. D., Von Cleve, E., \& Catalano, R. F. (1991). Reducing early childhood aggression: Results of a primary prevention program. Journal of the American Academy of Child \& Adolescent Psychiatry, 30(2), 208-217.

Health Canada. (2006). First Nations, Inuit and Aboriginal health: Suicide prevention. Retrieved January 26, 2010, from http://www.hc-sc.gc.ca/fniah-spnia/promotion/suicide/index-eng.php

Hoagwood, K., \& Erwin, H. D. (1997). Effectiveness of school-based mental health services for children: A 10-year research review. Journal of Child and Family Studies, 6(4), 435-451.

Hoagwood, K., Olin, S. S., Kerker, B. D., Kratochwill, T. R., Crowe, M., \& Saka, N. (2007). Empirically based school interventions targeted at academic and mental health functioning. Journal of Emotional and Behavioral Disorders, 15(2), 66-92.

Joyce, B., Calhoun, E., \& Hopkins, D. (1999). The new structure of school improvement: Inquiring schools and achieving students. Florence, KY: Taylor and Francis Group.

Kirby, M. (2005). Mental health reform for Canada in the $21^{\text {st }}$ century: Getting there from here. Canadian Public Policy, XXXI, S5-S12.

Kirby, M. J. L., \& Keon, W. J. (2006). Out of the shadows at last: Highlights and recommendations of the final report on mental health, mental illness and addiction. Retrieved November 11, 2008, from http://www.parl.gc.ca/39/1/parlbus/commbus/senate/com-e/soci-e/rep-e/pdf/rep02may06highe.pdf

Levesque, P., \& Manion, I. G. (2006). Better together: Child and youth mental health. Canadian Association of Principals Journal, 13(1), 27-28.

Manitoba Education, Citizenship and Youth. (2009). Intersectoral initiatives: Multi-system submission for students with profound emotional/behavioural disorders. Retrieved May 5, 2009, from http://www.edu.gov.mb.ca/k12/specedu/intersectoral/ebdl3/index.html

McEwan, K., Waddell, C., \& Barker, J. (2007). Bringing children's mental health "out of the shadows." Canadian Medical Association Journal, 17(4), 471-472.

Meldrum, L., Venn, D., \& Kutcher, S. (2009). Mental health in schools: How teachers have the power to make a difference. Health \& Learning Magazine, 8, 3-5.

Merry, S., McDowell, H., Wild, J., Bir, J., \& Cunliffe, R. (2004). A randomized placebo-controlled trial of a school-based depression prevention program. Journal of the American Academy of Child and Adolescent Psychiatry, 43(5), 538-548.

National Dissemination Center for Children with Disabilities. (2008). Emotional disturbance. Retrieved May 20, 2009, from

http://www.nichcy.org/Disabilities/Specific/Pages/EmotionalDisturbance.aspx.

Nova Scotia Department of Health. (2010). Mental health services: Services for children and youth. Halifax, NS: Author. Retrieved October 26, 2010, from http://gov.ns.ca/health/mhs/services_children.asp.

O’Brien, M. U., Weissberg, R. P., \& Shriver, T. P. (2003). Educational leadership for academic, social, and emotional learning. In M. J. Elias, H. Arnold, \& C. Steiger (Eds.), EQ+IQ: Best leadership practices for caring and successful schools (pp. 23-35). Thousand Oaks, CA: Corwin Press.

Ontario Healthy Schools Coalition. (May 9, 2008). Need for mental health to be included in the Ontario public health standards. Public correspondence. Available at http://www.chnig.org/downloads/OHSC_Briefing_Note_to_M_Kirby_re_Need_for_MH_in_OP HS-May_08-final.pdf

Ontario Ministry of Children and Youth Services. (2006). A shared responsibility: Ontario's policy framework for child and youth mental health. Toronto, ON: Author.

Ontario Ministry of Education. (2002). The Ontario curriculum planner: Special education companion. Toronto, ON: Queens Printer for Ontario. Retrieved October 26, 2010, from http://www.edu.gov.on.ca/eng/policyfunding/ocup/documents/speced2002.pdf. 
Ontario Ministry of Education. (2007). Foundations for a healthy school. Toronto, ON: Author. Retrieved October 26, 2010, from http://www.edu.gov.on.ca/eng/healthyschools/foundations.pdf.

Ontario Ministry of Education. (2008a). Character development initiative. Toronto, ON: Queen's Printer for Ontario. Retrieved February 20, 2010, from http://www.edu.gov.on.ca/eng/literacynumeracy/character.html

Ontario Ministry of Education. (2008b). Making Ontario's schools safer. Toronto, ON: Queen's Printer for Ontario. Retrieved February 20, 2010, from http://ogov.newswire.ca/ontario/GPOE/2008/01/30/c5273.html?lmatch=\&lang=_e.html

Ontario Ministry of Education. (2010). Healthy schools. Toronto, ON: Queen's Printer for Ontario. Retrieved February 20, 2010, from http://www.edu.gov.on.ca/eng/healthyschools/ infoTPA.html.

Ontario Physical Health and Health Education Association. (2010). Living school: Building healthier communities. Toronto, ON: Author. Retrieved February 20, 2010, from http://www.livingschool.ca/

Ontario Public Health Association. (2008). Ontario healthy schools coalition (OHSC). Retrieved October 26, 2010, from http://www.opha.on.ca/our_voice/collaborations/ohsc.shtml/).

Ottawa Carleton District School Board. (2009). Special education plan 2009. Ottawa, ON: Author. Retrieved January 24, 2010, from http://www.ocdsb.edu.on.ca/au_hi_ocdsb-publications.asp

Pervin, B., \& Gitterman, A. (2008). Student support leadership initiative: Planning and reporting template. Toronto, ON: Ministries of Education and Children and Youth Services.

Rones, M., \& Hoagwood, K. (2000). School-based mental health services: A research review. Clinical Child and Family Psychology Review, 3(4), 223-241.

Rothi, D. M., Leavey, G., \& Best, R. (2008). On the front-line: Teachers as active observers of pupils' mental health. Teaching and Teacher Education, 24, 1217-1231.

Santor, D., Short, K., \& Ferguson, B. (2009). Taking mental health to school: A policy-oriented paper on school-based mental health for Ontario. Ottawa, ON: The Provincial Centre of Excellence for Child and Youth Mental Health at CHEO.

Saskatchewan Health. (2007). Mental health services. Retrieved February 20, 2010, from http://www.health.gov.sk.ca/mental-health.

Sherman, M. (2008). A call to arms: Children's mental health. School Administrator, 65(1), 26-29.

Shochet, I. M., Dadds, M. R., Holland, D., Whitefield, K., Harnett, P., \& Osgarby, S. (2001). The efficacy of a universal school-based program to prevent adolescent depression. Journal of Clinical Child Psychology, 30(3), 303-315.

Skalski, A. K., \& Smith, M. J. (2006). Responding to the mental health needs of students. Principal Leadership, 7(1), 12-15.

Steenkamp, P., \& Wright, J. (2008). Memorandum: Student support leadership initiative. Toronto, ON: Ontario Ministries of Education and Children and Youth Services.

Stein, B. D., Kataoka, S., Jaycox, L. H., Wong, M., Fink, A., Escudero, P., et al. (2002). Theoretical basis and program design of a school-based mental health intervention for traumatized immigrant children: A collaborative research partnership. The Journal of Behavioral Health Services and Research, 29(3), 318-326.

Stern, R. (2009). Social and emotional learning: What is it? How can we use it to help our children? Retrieved October 26, 2010, from http://www.aboutourkids.org/articles/social_emotional_learning what_it_how_can_we_use_it_help_our_children

Twemlow, S. D., Fonagy, P., Sacco, F. C., Gies, M. L., Evans, R., \& Ewbank, R. (2001). Creating a peaceful school learning environment: A controlled study of an elementary school intervention to reduce violence. American Journal of Psychiatry, 158, 808-810.

UNICEF Canada. (2007). What's rights for some: $18 @ 18$. A portrait of Canada's first generation growing up under the UN Convention on the Rights of the Child. Toronto, ON: Author.

U. S. Department of Health and Human Services. (2001). Mental health: Culture, race, and ethnicity $-A$ supplement to mental health: A report of the surgeon general. Rockville, MD: Author. 
Waddell, C., Offord, D. R., Shepherd, C. A., Hua, J. M., \& McEwan, K. (2002). Child psychiatric epidemiology and Canadian public policy-making: The state of the science and the art of the possible. Canadian Journal of Psychiatry, 47(9), 825-832.

Waddell, C., Peters, R. D., Hua, J. M., McEwan, K., \& Garland, O. M. (2007). Preventing mental disorders in children: A systematic review to inform policy-making. Canadian Journal of Public Health, 98(3), 166-173.

Waddell, C., \& Shepherd, C. (2002). Prevalence of mental disorders in children and youth. Vancouver, BC: Mental Health Evaluation and Community Consultation Unit, University of British Columbia.

Wagner, M., Kutash, K., Duchnowski, A. J., Epstein, M. H., \& Sumi, W. C. (2005). The children and youth we serve: A national picture of the characteristics of students with emotional disturbances receiving special education. Journal of Emotional and Behavioral Disorders, 13(2), 79-96.

Wahl, O. F. (2002). Children's views of mental illness: A review of the literature. American Journal of Psychiatric Rehabilitation Skills, 6(2), 134-158.

Walter, H. J., Gouze, K., \& Lim, K. G. (2006). Teachers' beliefs about mental health needs in inner city elementary schools. Journal of the American Academy of Child and Adolescent Psychiatry, 45(1), $61-68$.

Waxman, R. P., Weist, M. D., \& Benson, D. M. (1999). Toward collaboration in the growing educationmental health interface. Clinical Psychology Review, 19(2), 239-253.

Weare, K., \& Markham, W. (2005). What do we know about promoting mental health through schools? Promotion \& Education, XII(3-4), 118-122.

World Health Organization. (2001). The world health report 2001 - Mental health: New understanding, new hope. Geneva, Switzerland: World Health Organization. Retrieved January 26, 2010, from http://www.who.int/whr/2001/en/

World Health Organization. (2009). Mental health: A state of well-being. Retrieved February 20, 2010, from http://www.who.int/features/factfiles/mental_health/en/index.html.

Wyn, J., Cahill, H., Holdsworth, R., Rowling, L., \& Carson, S. (2000). MindMatters, a whole-school approach promoting mental health and wellbeing. Australian and New Zealand Journal of Psychiatry, 34(4), 594-601.

\section{Author's Note}

Correspondence concerning this article should be addressed to Dr. Jess Whitley, Assistant Professor, Faculty of Education, University of Ottawa, 145 Jean Jacques Lussier, Ottawa, ON, K1N 6N5. Email: jwhitley@uottawa.ca 